\title{
Anomalous electron density events in the quiet summer ionosphere at solar minimum over Millstone Hill
}

\author{
A. V. Pavlov ${ }^{1}$ and M. J. Buonsanto ${ }^{2}$ \\ ${ }^{1}$ Institute of Terrestrial Magnetism, Ionosphere and Radio-Wave Propagation, Russia \\ Academy of Science (IZMIRAN), Troitsk, Moscow Region, 142092, Russia \\ ${ }^{2}$ Massachusetts Institute of Technology, Haystack Observatory, Westford, MA 01886, USA
}

Received: 7 July 1997 / Revised: 17 November 1997 / Accepted: 19 November 1997

\begin{abstract}
This study compares the observed behavior of the $F$ region ionosphere over Millstone Hill with calculations from the IZMIRAN model for solar minimum for the geomagnetically quiet period $23-25$ June 1986, when anomalously low values of $h m F 2(<200$ $\mathrm{km})$ were observed. We found that these low values of $h m F 2$ (seen as a $G$ condition on ionograms) exist in the ionosphere due to a decrease of production rates of oxygen ions resulting from low values of atomic oxygen density. Results show that determination of a $G$ condition using incoherent scatter radar data is sensitive both to the true concentration of $\mathrm{O}^{+}$relative to the molecular ions, and to the ion composition model assumed in the data reduction process. The increase in the $\mathrm{O}^{+}+\mathrm{N}_{2}$ loss rate due to vibrationally excited $\mathrm{N}_{2}$ produces a reduction in $N m F 2$ of typically $5-10 \%$, but as large as $15 \%$, bringing the model and data into better agreement. The effect of vibrationally excited $\mathrm{NO}^{+}$ions on electron densities is negligible.
\end{abstract}

Key words. Ionosphere (Ion chemistry and composition; Ionosphere-atmosphere interactions; Mid-latitude ionosphere).

\section{Introduction}

One of the most striking features of the mid-latitude ionospheric $F$ region is the "G condition" seen on ionograms, when the critical frequency of the $F 2$ layer is lower than the critical frequency of the $F 1$ layer.

This phenomenon occurs frequently in the quiet ionosphere at solar minimum during summer and

Correspondence to: M. J. Buonsanto during geomagnetically disturbed periods, when the peak density of the $F 1$ layer which is composed mostly of the molecular ions $\mathrm{NO}^{+}$and $\mathrm{O}_{2}^{+}$is larger than the peak density of the $F 2$ layer which is dominated by $\mathrm{O}^{+}$ ions. The result is a low hmax value (below $200 \mathrm{~km}$ ) observed by ionograms, so that no information is obtainable above this height. This phenomenon has been studied by Buonsanto (1990) using ionosonde data from two mid-latitude stations, Boulder and Wallops Island, by Oliver (1990) using Millstone Hill incoherent scatter data, and by Fukao et al. (1991) using data from the middle and upper atmosphere (MU) radar in Japan. Model results show that $\mathrm{O}^{+}$can become a minor ion in the $F$ region during disturbed conditions at high latitudes (Banks et al., 1974; Schunk et al., 1975), and observations at EISCAT confirm this (e.g., Häggström and Collis, 1990). The present work provides further evidence for the occurrence of this feature during summer solar minimum in the quiet midlatitude ionosphere. We compare modeled $F$ peak densities with those measured by the Millstone Hill incoherent scatter radar (ISR) during the undisturbed period 23-25 June 1986.

This feature could be explained either by decreases in the densities of $\mathrm{O}^{+}\left({ }^{4} S\right)$, or by increases in the densities of the molecular ions. These species concentrations can be changed in several ways. A decrease in neutral atomic oxygen density results in a decrease in the production of $\mathrm{O}^{+}$by photoionization and photoelectron impact. An increase in $\left[\mathrm{N}_{2}\right]$ and $\left[\mathrm{O}_{2}\right]$ results in an increase in the $\mathrm{O}^{+}$ recombination rate, simultaneously decreasing $\left[\mathrm{O}^{+}\right]$and increasing $\left[\mathrm{NO}^{+}\right]$and $\left[\mathrm{O}_{2}^{+}\right]$.

A wind-induced plasma drift velocity, $W_{d}$, along the magnetic field line arising from the horizontal meridional component of the neutral wind also affects the concentrations of the $F$ region ions. An equatorward wind lifts the ionization to higher altitudes where the decreased $\mathrm{O}^{+}$loss rate leads to a higher $\mathrm{O}^{+} F$ layer density. Conversely, a poleward wind forces $\mathrm{O}^{+}$ions to lower altitudes where the increased recombination rate decreases $\left[\mathrm{O}^{+}\right]$and increases $\left[\mathrm{NO}^{+}\right]$and $\left[\mathrm{O}_{2}^{+}\right]$. 
In this work we compare the observed diurnal variations of $N m F 2$, electron and ion temperature $\left(T_{e}\right.$ and $T_{i}$ ) at the $F$ peak, as well as altitude profiles of $T_{e}, T_{i}$ and electron density, $N_{e}$, with values obtained from a comprehensive ionospheric model to see how well current theory explains the observed ionospheric behavior during a quiet interval at summer solar minimum. We investigate whether the changes in $[\mathrm{O}],\left[\mathrm{N}_{2}\right]$, and $\left[\mathrm{O}_{2}\right]$ given by the MSIS-86 model and the observed plasma drift velocity can explain the occurrence of the $G$ condition observed by the Millstone Hill ISR on 24 June 1986.

The major loss process for both $\mathrm{NO}^{+}$and $\mathrm{O}_{2}^{+}$is dissociative recombination with electrons. Ions may recombine at markedly different rates depending on their degree of vibrational excitation. The vibrational distribution $\mathrm{O}_{2}^{+}(\mathrm{v})$ in the daytime ionosphere was computed by Fox (1986) for vibrational levels 1-3. The dissociative recombination coefficients for $\mathrm{O}_{2}^{+}(\mathrm{v}>0)$ ions are close to those for $\mathrm{O}_{2}^{+}(\mathrm{v}=0)$ ions (Zipf, 1980, 1988; Bates, 1988), so we ignore effects of vibrational excitation on the $\mathrm{O}_{2}^{+}$recombination rate and calculate $\left[\mathrm{O}_{2}^{+}\right]$by solving a single continuity equation using the dissociative recombination rate coefficient for $\mathrm{O}_{2}^{+}(\mathrm{v}=0)$ ions.

However, for $\mathrm{NO}^{+}$ions, the dissociative recombination rate coefficients for vibrational levels $\mathrm{v}=1$ and $\mathrm{v}=2$ are much smaller that for $\mathrm{v}=0$ (Bardsley, 1983), so vibrationally excited $\mathrm{NO}^{+}$ions may form a significant proportion of the total $\mathrm{NO}^{+}$density, as suggested by Yonezawa (1968). Pavlov (1987) also investigated the possibility that vibrationally excited $\mathrm{NO}^{+}$ions could influence the overall recombination rate of $\mathrm{NO}^{+}$, but this effect was found to be unimportant. Our knowledge of the major production and loss processes for $\mathrm{NO}^{+}(\mathrm{v}>0)$ ions have evolved considerably (Bardsley, 1983; Dobler et al., 1983; Heninger et al., 1986). Here we investigate the possible effects of vibrationally excited $\mathrm{NO}^{+}$ions on the electron density for the period of $23-$ 25 June 1986.

In an earlier study, Richards et al. (1989) found that vibrationally excited $\mathrm{N}_{2}$ had little effect on the electron density and temperature during the geomagnetically quiet day 18 September 1984 at solar minimum. However, the role of $\mathrm{N}_{2}(\mathrm{v})$ at solar minimum may be larger in summer (Pavlov, 1994) than at equinox, and our present task is to examine the effect of $\mathrm{N}_{2}(\mathrm{v})$ on the electron density and temperature for the summer period 23-25 June 1986.

\section{IZMIRAN model}

The model of the thermal plasma in the ionosphere and plasmasphere used in the present work has been steadily developed over several years. The enhanced and updated version of the IZMIRAN model is described in detail by Pavlov (1997) and hence only a brief description will be given here.

The IZMIRAN model is a one-dimensional model that uses a dipole approximation to the Earth's mag- netic field and takes into account the offset between the geographic and geomagnetic axes. In the model. coupled time dependent equations of continuity, momentum, and energy balance for electrons, and $\mathrm{O}^{+}\left({ }^{4} S\right), \mathrm{H}^{+}$, and $\mathrm{He}^{+}$ions are solved along a centered-dipole magnetic field line for the concentrations, field-aligned diffusion velocities, and temperatures of ions and electrons from a base altitude $(160 \mathrm{~km})$ in the Northern Hemisphere through the plasmasphere to the same base altitude in the Southern Hemisphere. Electron heating due to photoelectrons is provided by a solution of the Boltzmann equation for photoelectron flux along the entire flux tube using the method of Krinberg and Tashchilin (1984) on the same field line grid that is used in solving for the densities and temperatures. In the altitude range $120-700 \mathrm{~km}$ in the Northern and Southern Hemispheres the model also solves time dependent continuity equations for $\mathrm{O}^{+}\left({ }^{2} D\right), \mathrm{O}^{+}\left({ }^{2} P\right), \mathrm{NO}^{+}, \mathrm{O}_{2}^{+}, \mathrm{N}_{2}^{+}$, vibrationally excited molecular nitrogen, $\mathrm{N}_{2}(\mathrm{v})$, at the first five vibrational levels $\mathrm{v}=1-5$, and the momentum equations for the horizontal components of the thermospheric wind. Time dependent continuity equations for $\mathrm{O}\left({ }^{1} D\right)$ are solved in the region between 120 and $1500 \mathrm{~km}$ in altitude.

The model has options to calculate either a Boltzmann or a non-Boltzmann distribution of $\mathrm{N}_{2}(\mathrm{v})$. For solar minimum, Pavlov and Namgaladze (1988) found no significant difference between electron density and temperature calculated using a Boltzmann distribution and a non-Boltzmann distribution of $\mathrm{N}_{2}(\mathrm{v})$, so in this study we assume a Boltzmann distribution.

The ion-atom interchange rate coefficients, $K_{\mathrm{v}}$, of $\mathrm{O}^{+}\left({ }^{4} S\right)$ ions with $\mathrm{N}_{2}(\mathrm{v}>0)$ were measured by Schmeltekopf et al. (1986) and Ferguson et al. (1984) for $T_{n}=T_{i}=300 \mathrm{~K}$. Van Zandt and O'Malley (1973) determined the dependence of these rate coefficients on $T_{n}$ by using the results of Schmeltekopf et al. (1968) and a simple theoretical model of these reactions. Pavlov (1988) modified this approach by taking into account the dependence of the $\mathrm{N}_{2}(\mathrm{v}>0)$ rate coefficients on the effective temperature, and adopting the rate coefficient for $\mathrm{N}_{2}(\mathrm{v}=0)$ given by Albritton et al. (1977).

The rate coefficient, $K_{\mathrm{D}}$, for quenching of $\mathrm{O}^{+}\left({ }^{2} D\right)$ by atomic oxygen has not been measured in the laboratory. Widely diverging values of $10^{-10} \mathrm{~cm}^{3} \mathrm{~s}^{-1}$ (Oppenheimer et al., 1977; Fox and Dalgarno, 1985) and $5 \times 10^{-12} \mathrm{~cm}^{3} \mathrm{~s}^{-1}$ have been proposed from comparison between measured and modeled $\mathrm{N}_{2}^{+}$, and the differing points of view have been discussed by Torr and Torr (1982), Abdou et al. (1984), Ferguson (1984), and Fox and Dalgarno (1985). Fox and Dalgarno (1985) developed a very sophisticated model to calculate the vibrational distribution of $\mathrm{N}_{2}^{+}$. They found that rate constants of $10^{-11}$ and $10^{-10}$ could be equally successful in reproducing the observed $\mathrm{N}_{2}^{+}$densities considered by Oppenheimer et al., (1977) depending on other model assumptions.

This discussion illustrates that laboratory measurements of both the quenching of $\mathrm{O}^{+}\left({ }^{2} D\right)$ by atomic oxygen, and the temperature dependence of the ionatom interchange rate coefficients, $K_{\mathrm{v}}$, of $\mathrm{O}^{+}\left({ }^{4} S\right)$ ions 
with $\mathrm{N}_{2}(\mathrm{v}>0)$ are highly desirable. Our model of the thermal plasma in the ionosphere and plasmasphere includes the option to use three sets of models of these rate coefficients.

In model A the rate coefficient $K_{D}=10^{-10} \mathrm{~cm}^{3} \mathrm{~s}^{-1}$ and the rate coefficients $K_{\mathrm{v}}$ are determined by the equations given by Pavlov (1988). This approach was used in the IZMIRAN model (Pavlov, 1994, 1996; Pavlov and Buonsanto, 1997).

Model B uses $K_{\mathrm{D}}=5 \times 10^{-12} \mathrm{~cm}^{3} \mathrm{~s}^{-1}$ and the recombination rate coefficients of $\mathrm{O}^{+}\left({ }^{4} S\right)$ ions with $\mathrm{N}_{2}(\mathrm{v}>0)$ measured by Schmeltekopf et al. (1968) for $T_{n}=T_{i}=300 \mathrm{~K}$.

In model $\mathrm{C}$ the rate coefficient $K_{D}=5 \times 10^{-12} \mathrm{~cm}^{3} \mathrm{~s}^{-1}$, and the ratios of the recombination rate coefficients of $\mathrm{O}^{+}\left({ }^{4} S\right)$ ions with $\mathrm{N}_{2}(\mathrm{v}>0)$ to the rate coefficients of $\mathrm{O}^{+}\left({ }^{4} S\right)$ ions with $\mathrm{N}_{2}(0)$ are the same as measured by Schmeltekopf et al. (1968) for $T_{n}=T_{i}=300 \mathrm{~K}$, i.e., $K_{1}(T) / K_{0}(T)=1, K_{2}(T) / K_{0}(T)=38, K_{3}(T) / K_{0}(T)=$ $85, K_{4}(T) / K_{0}(T)=220, K_{5}(T) / K_{0}(T)=270$, where $T$ is the effective temperature given by St. Maurice and Torr (1978). Model C assumes that the temperature dependence of these reaction rates are the same as for unexcited $\mathrm{N}_{2}$, i.e., are as given by St. Maurice and Torr (1978). This approach is used in the FLIP model (Torr et al., 1990).

In this study we employ model $\mathrm{A}$ and compare results with those from models $\mathrm{B}$ and $\mathrm{C}$ to evaluate the effects of the uncertainty in the rate of quenching of $\mathrm{O}^{+}\left({ }^{2} D\right)$ by atomic oxygen on calculated electron densities and temperatures.

The three key inputs to the IZMIRAN model are the concentrations and temperatures of the neutral constituents, the solar EUV fluxes, and the plasma drift velocity. To simulate magnetic storm effects on the neutral atmosphere the MSIS-86 model (Hedin, 1987) was run using 3 hour $A_{p}$ indices, while the solar EUV fluxes are from the EUVAC model (Richards et al., 1994a). At night we include ionization by scattered solar 121.6, 102.6 and $58.4 \mathrm{~nm}$ fluxes.

The wind-induced plasma drift velocity is $W_{d}=U \cos I$, where $U$ is the horizontal neutral wind in the magnetic meridian (positive southward), and $I$ is the magnetic dip angle. We calculate an equivalent neutral wind from the $h m F 2$ measurements using the method of Richards (1991). Our implementation of the Richards(1991) method is described by Pavlov and Buonsanto (1997). Uncertainties in the calculation of $W_{d}$ result from errors in calculation of the zero wind $h m F 2$ and in the constant of proportionality $\alpha=\Delta h / \Delta U$ due to use of the MSIS- 86 model and assumptions about rate coefficients and cross sections, where $\Delta h$ is the change in $h m F 2$ due to a change in the meridional wind $\Delta U$. In the Southern Hemisphere where we do not have the observed $h m F 2$, we use $h m F 2$ given by the IRI model (Bilitza, 1990) to calculate an equivalent plasma drift velocity.

The distribution of ionization in the topside ionosphere and plasmasphere is strongly controlled by the geomagnetic field, and therefore the IZMIRAN model calculations may be considered valid up to $\mathrm{L}=6$, where the dipole approximation of the geomagnetic field is reasonably accurate (Krinberg and Tashchilin, 1984). The model cannot give a correct description of the ionosphere between $-20^{\circ}$ and $20^{\circ}$ magnetic latitude, as that requires taking into account the exchange of ions and electrons between magnetic flux tubes because of the action of electromagnetic drift.

\section{Millstone Hill results}

\subsection{Diurnal and altitude variations}

Figure 1 shows the diurnal variations of the measured and modeled equivalent plasma drift velocity $\left(W_{\mathrm{D}}\right), h m F 2$, and $N m F 2$ for the period 23-25 June 1986. This was a geomagnetically quiet period (daily $A p$ in the range 3-7 and 3-h $A p$ in the range 2-18) at solar minimum $(F 10.7=66)$. The top panel shows $W_{\mathrm{D}}$ obtained from standard analysis of incoherent scatter radar data (crosses), and $W_{\mathrm{D}}$ obtained from the observed $h m F 2$ using the modified Richards method (lines). The middle panel shows measured (crosses) and modeled (lines) $h m F 2$, and the bottom panel shows measured (crosses) and modeled (lines) $N m F 2$.

The top panel of Fig. 1 shows a large observed upward drift (crosses) due to a predominantly equatorward wind which is typical of these summer solar minimum conditions (Hagan, 1993).

Anomalous measured $h m F 2$ values $\leq 20 \mathrm{~km}$ were measured at $0451,0702,0738$, and 0850 LT on 24 June. To study this anomaly in $h m F 2$ we used three neutral atmosphere models in our calculations. Solid lines in Fig. 1 show the results obtained using the standard MSIS-86 model. Figure 1 also gives the calculated $N m F 2$, $h m F 2$, and $W_{\mathrm{D}}$ from the modified Richards methods using two adjusted MSIS-86 models for all altitudes between 0500 LT and 0800 LT on 24 June. Dashed lines show results when the atomic oxygen density was decreased by a factor of 1.6, and dotted lines show results when the $\mathrm{N}_{2}$ and $\mathrm{O}_{2}$ densities were increased by a factor of 2 at all altitudes and locations during this time interval. No adjustments were made to the $[\mathrm{O}],\left[\mathrm{N}_{2}\right]$, and $\left[\mathrm{O}_{2}\right]$ values at any other times. During the period 0500-0800 LT on 24 June, the best agreement between the measured $W_{\mathrm{D}}$ and $W_{\mathrm{D}}$ from the modified Richards method, and between the measured and modeled $h m F 2$ occurs when the MSIS-86 atomic oxygen adjustment is used.

A decrease in the MSIS O density at other times also would help explain the difference between $W_{\mathrm{D}}$ obtained from the ISR and $W_{\mathrm{D}}$ obtained from the modified Richards method at those times. A decrease in MSIS O density by a factor 1.6 would produce an unrealistically low $N m F 2$ at most times. One can note from the bottom panel of Fig. 1, however, that the modeled $N m F 2$ is a little larger than the observed $N m F 2$ at most times. Thus, a small decrease in MSIS $\mathrm{O}$ density at times before and after the interval $0500-0800$ LT on 24 June would help reconcile the drifts at those times, while the resulting small decreases in the modeled $N m F 2$ would 

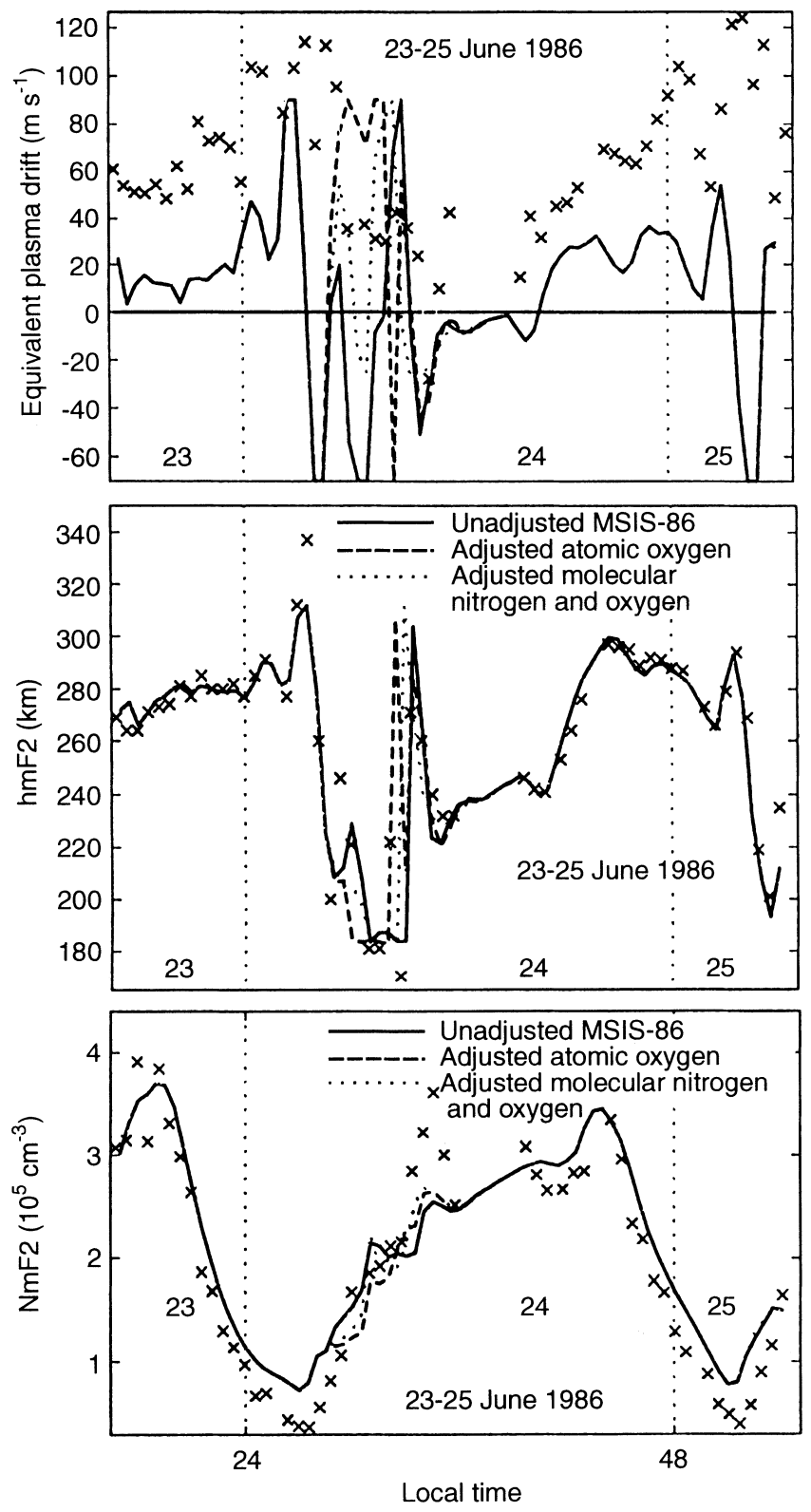

Fig. 1. Observed (crosses) and calculated (lines) parameters above Millstone Hill for 23-25 June 1986. Top: equivalent plasma drift velocity; middle:hmF2; bottom:NmF2. The solid lines show results from the IZMIRAN model using the unadjusted MSIS-86 neutral atmosphere model. Dashed and dotted lines show effects of adjustments to the MSIS-86 model between 0500 LT and 0800 LT on 24 June at all altitudes. Dashed lines show results when the MSIS86 model [O] was decreased by a factor 1.6. Dotted lines show results when the MSIS-86 model $\left[\mathrm{N}_{2}\right]$ and $\left[\mathrm{O}_{2}\right]$ were increased by a factor of 2

actually improve the agreement between the measured and modeled $\mathrm{NmF2}$. One would expect that some decreases in the MSIS $\mathrm{O}$ density before and after the interval 0500-0800 LT should be needed, as abrupt changes at 0500 and $0800 \mathrm{LT}$ are not physically realistic.

While the MSIS- 86 model is the best available model of the neutral upper atmosphere, it is well known to be subject to errors in modeling the neutral composition on specific days and locations. As a result of a limited number of measurements of number densities, not all
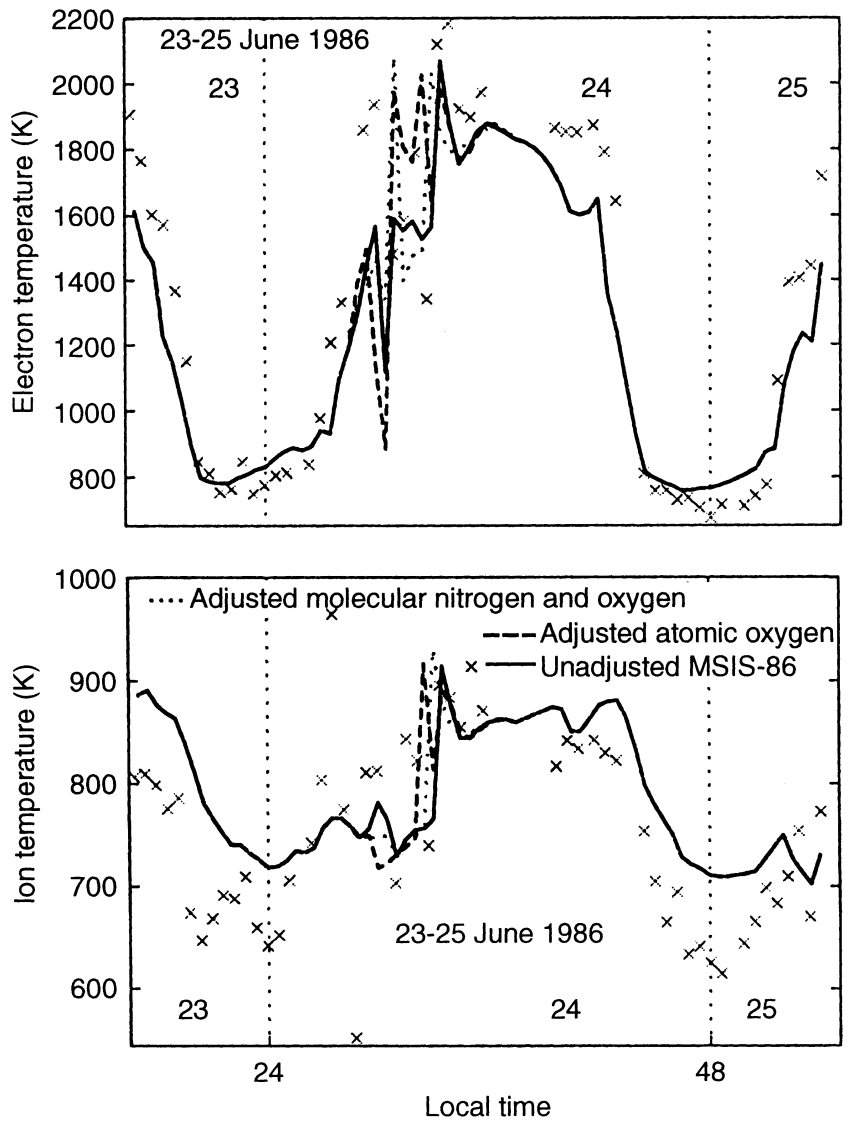

Fig. 2. Observed (crosses) and calculated (lines) electron (top) and ion (bottom) temperatures at the height of the $F 2$ peak for 23-25 June 1986. The solid, dashed, and dotted lines are the same as for Fig. 1

solar-geophysical conditions are well represented in these models. The temperature structure and composition of the quiet midlatitude thermosphere is governed primarily by the absorption of solar radiation, chemical reactions, molecular and eddy diffusion and heat conduction, radiative cooling, and global wind structure. Analytical formulae and a set of indexes, as used in the MSIS-86 model to calculate number densities, cannot describe with great accuracy real changes of neutral composition at all times and locations.

Figure 2 shows the diurnal variations of the measured and modeled electron and ion temperature at the $F 2$ peak altitude. Solid lines show model results obtained using the unadjusted MSIS-86 model, dashed lines show model results obtained using the adjusted MSIS-86 [O] density, and dotted lines show results obtained using the adjusted MSIS-86 $\left[\mathrm{N}_{2}\right]$ and $\left[\mathrm{O}_{2}\right]$ densities. For most of the period, there is reasonable agreement between the measured and modeled temperatures, and the results do not allow us to determine whether an adjustment to the MSIS- 86 model is needed during the period $0500-0800$ LT on 24 June.

Figures 3 and 4 compare the measured (crosses and squares) and modeled altitude profiles of $N_{e}$, and $T_{e}$ and $T_{i}$ at $0732 \mathrm{LT}$ on 24 June. As the figures show, the modeled profiles agree best with the measured profiles when the MSIS-86 model with the adjusted atomic 


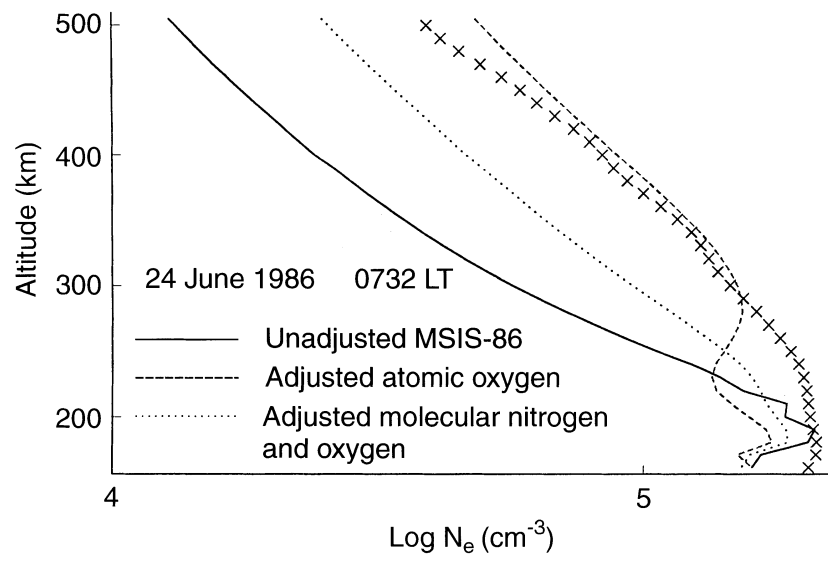

Fig. 3. Observed (crosses) and calculated (lines) electron density at 0732 LT for 24 June 1986. The solid, dashed, and dotted lines are the same as for Fig. 1

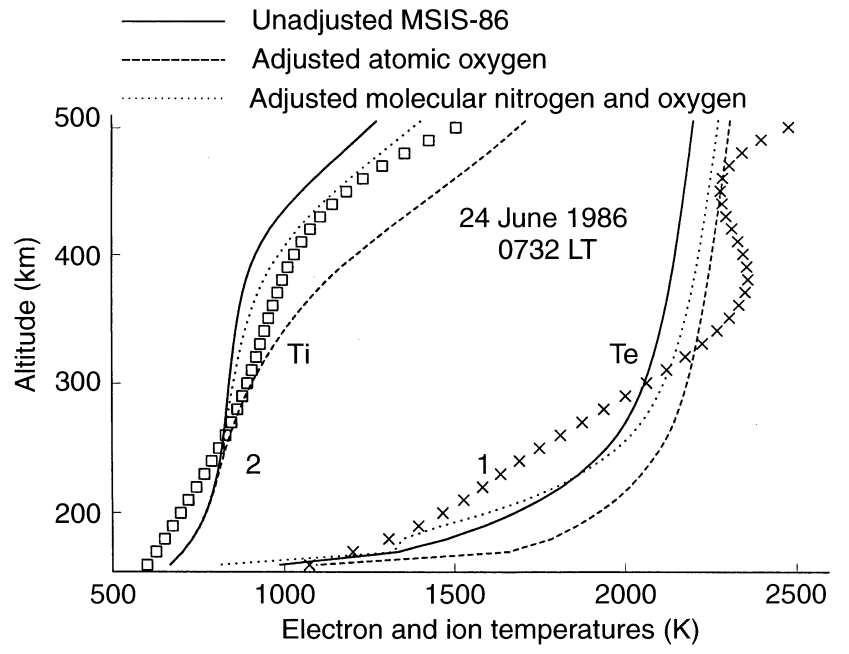

Fig. 4. Observed (symbols) and calculated (lines) electron (curves 1) and ion (curves 2) temperature at 0732 LT for 24 June 1986. The solid, dashed, and dotted lines are the same as for Fig. 1

oxygen density is used in the IZMIRAN model. There is a large disagreement between the measured and modeled electron densities when the original MSIS- 86 model or the MSIS- 86 model with the adjusted $\mathrm{N}_{2}$ and $\mathrm{O}_{2}$ density is used in the calculations of $N_{e}$. The disagreement in $N_{e}$ increases with the altitude and approaches a factor of 6 within the altitude range $400-500 \mathrm{~km}$. The IZMIRAN model gives altitude profiles of $T_{e}$ and $T_{i}$ in reasonable agreement with the measured $T_{e}$ and $T_{i}$.

For understanding the differences between the measured and modeled $N_{e}(z)$ it should be noted that during the period $0500-0800$ LT on 24 June the IZMIRAN model with the adjusted atomic oxygen density gives an upward vertical plasma drift $\left(W_{d}>0\right)$, while $W_{d}<0$ is calculated by the IZMIRAN model when the original MSIS-86 model or the adjusted MSIS-86 $\left[\mathrm{N}_{2}\right]$ and $\left[\mathrm{O}_{2}\right]$ are used (see upper panel of Fig. 1). While the upward plasma drift lifts the ionization to higher altitudes where the $\mathrm{O}^{+}$loss rate is smaller, this is compensated by a smaller production rate due to the decrease in MSIS [O] by a factor of 1.6 (dashed lines in Fig. 1-4), so that a $G$ condition still results. For the other two cases (solid and dotted lines in Fig. 1-4), the downward plasma drift moves $\mathrm{O}^{+}$ions to lower altitudes where their recombination rate is larger, again resulting in a $\mathrm{G}$ condition. However, the downward plasma drift results in a very low $N_{e}$ above $250 \mathrm{~km}$ in disagreement with the measurements.

The reactions of $\mathrm{O}^{+}\left({ }^{4} S\right)$ with $\mathrm{N}_{2}$ and $\mathrm{O}_{2}$ are sources of $\mathrm{NO}^{+}$and $\mathrm{O}_{2}^{+}$. Decreases in the production rate of $\mathrm{O}^{+}\left({ }^{4} S\right)$ due to decreases in $[\mathrm{O}]$ result in decreases in $\left[\mathrm{NO}^{+}\right]$and $\left[\mathrm{O}_{2}^{+}\right]$, while decreases in $\left[\mathrm{O}^{+}\left({ }^{4} S\right)\right]$ due to increases in $\left[\mathrm{N}_{2}\right]$ and $\left[\mathrm{O}_{2}\right]$ results in increases in $\left[\mathrm{NO}^{+}\right]$ and $\left[\mathrm{O}_{2}^{+}\right]$. The time behavior of $\left[\mathrm{NO}^{+}\right]$and $\left[\mathrm{O}_{2}^{+}\right]$affects the modeled $N_{e}(z)$ and $h m F 2$. Differences in the modeled $h m F 2$ produces the differences in $W_{d}$ which influence the altitude profiles of the daytime modeled electron densities on 24 June.

\subsection{Vibrationally excited nitrogen and $\mathrm{O}^{+}\left({ }^{2} \mathrm{D}\right)$ ions}

In the IZMIRAN model the loss rate of $\mathrm{O}^{+}\left({ }^{4} S\right)$ ions is

$L=\sum_{j=0}^{5} K_{j}\left[N_{2}(j)\right]+\gamma\left[\mathrm{O}_{2}\right]$

where $K_{j}$ and $\gamma$ are the recombination rate coefficients of $\mathrm{O}^{+}\left({ }^{4} S\right)$ ions with $\mathrm{N}_{2}(j=0-5)$ and $\mathrm{O}_{2},\left[N_{2}(0)\right]=\left[N_{2}\right] /(1+\alpha), \alpha$ is the vibrational quanta (a measure of the vibrational energy of $\mathrm{N}_{2}(\mathrm{v})$ ), and $\left[\mathrm{N}_{2}\right]$ and $\left[\mathrm{O}_{2}\right]$ are obtained from the MSIS-86 model.

The ability of the IZMIRAN model to reproduce the measured $h m F 2$ and $N m F 2$ is illustrated in Fig. 5. The top panel shows the difference between the observed and the modeled $h m F 2$, while the bottom panel gives the ratio of the observed to the modeled $N m F 2$. The solid line shows model results when vibrationally excited $\mathrm{N}_{2}$ is included in calculations of the $\mathrm{O}^{+}\left({ }^{4} S\right)$ loss rate as given by Eq. (1). The dashed lines show model results when vibrationally excited $\mathrm{N}_{2}$ is not included. These two curves used the IZMIRAN model (model A) as described in Sect. 2. The dotted curve gives results from model $\mathrm{C}$, and the crosses give results from model $\mathrm{B}$ as described in Sect. 2. We will discuss the differences between the results of models A, B, and C later in this section. The solid and dashed curves in Fig. 5 show that the increase in the $\mathrm{O}^{+}+\mathrm{N}_{2}$ loss rate due to vibrationally excited $\mathrm{N}_{2}$ produces reductions in $\mathrm{NmF} 2$ of typically 5 $10 \%$, but as large as $15 \%$.

For a fixed altitude, local time, and solar and geomagnetic activity level the neutral temperature in summer is larger than the neutral temperature at equinox at a given mid-latitude location. As a result, the vibrational temperature is larger in summer than at equinox, and the summer decrease in $N m F 2$ due to $\mathrm{N}_{2}(\mathrm{v}>0)$ shown in Fig. 5 is a little larger than that calculated for the magnetically quiet solar minimum period 18 September 1984 by Richards et al. (1989).

The effect of vibrationally excited nitrogen on $N_{e}$ is more pronounced in summer than in winter and 

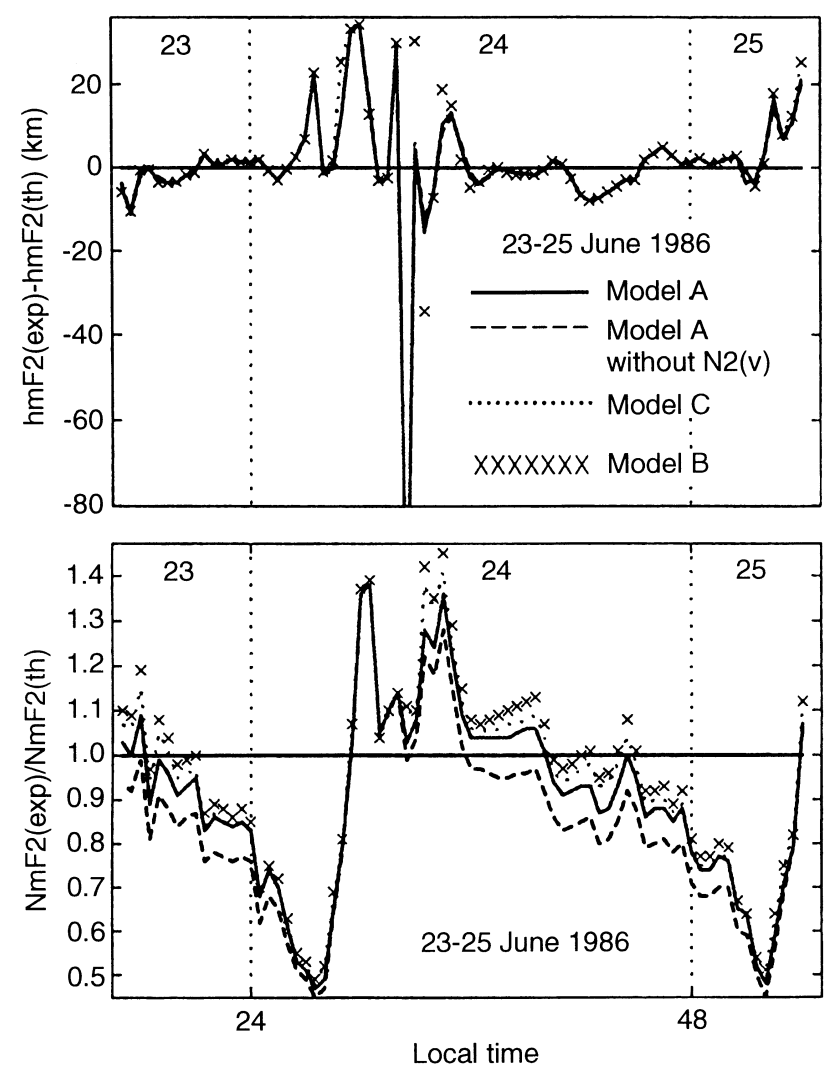

Fig. 5. IZMIRAN model results for 23-25 June 1986 at Millstone Hill. Top: differences between the measured $h m F 2$ (exp) and modeled $h m F 2$ (th); bottom: ratios of the measured $N m F 2$ (exp) to the modeled $N m F 2$ (th). The MSIS-86 model with the adjusted atomic oxygen density is used in the IZMIRAN model between 0500 LT and 0800 LT on 24 June at all altitudes. The solid lines give results including effects of $\mathrm{N}_{2}(\mathrm{v})$ and using the rate coefficient for quenching of $\mathrm{O}^{+}\left({ }^{2} D\right)$ by atomic oxygen $K_{\mathrm{D}}=10^{-10} \mathrm{~cm}^{3} \mathrm{~s}^{-1}$ (model A). The dashed lines show results using $K_{\mathrm{D}}=10^{-10} \mathrm{~cm}^{3} s^{-1}$ (model A), but without effects of $\mathrm{N}_{2}(\mathrm{v})$. The dotted lines (model $\mathrm{C}$ ) and crosses (model B) show results including effects of $\mathrm{N}_{2}(\mathrm{v})$ and using $K_{\mathrm{D}}=5 \times 10^{-12} \mathrm{~cm}^{3} \mathrm{~s}^{-1}$

increases with increasing solar activity. For daytime conditions this effect is mainly dependent on the values of $T_{e}$, neutral temperatures, and $\left.\left[\mathrm{O}_{2}\right] / \mathrm{N}_{2}\right]$ at $F$ region altitudes. Richards et al. (1994b) found that at solar maximum the inclusion of $\mathrm{N}_{2}(\mathrm{v})$ in the FLIP model reduces the calculated quiet daytime $N_{e}$ by about $15 \%$ in winter and by about $40 \%$ in summer. Pavlov et al. (submitted 1998) compare measurements of the ionospheric $F$ region at Millstone Hill during the severe geomagnetic disturbances of 5-11 June, 1991 at solar maximum with results from the IZMIRAN and FLIP time-dependent mathematical models of the Earth's ionosphere and plasmasphere and the Millstone Hill semi-empirical model and found that increases in the $\mathrm{O}^{+}+\mathrm{N}_{2}$ loss rate due to $\mathrm{N}_{2}(v)$ result in a factor $\sim 2$ reduction in the daytime $F 2$ peak electron density.

Figure 5 shows some significant differences between the measured and modeled $h m F 2$ and between the measured and modeled $N m F 2$. A quantitative measure of the accuracy of the model results is obtained by computing root mean square (rms) errors as follows:

$$
\begin{aligned}
& \varepsilon_{1}=\left\{\sum_{s=1}^{M}\left[h m F_{2}(\exp )_{s}-h m F_{2}(\mathrm{th})_{s}\right]^{2} / M\right\}^{1 / 2} \\
& \varepsilon_{2}=\left\{\sum_{s=1}^{M}\left[N m F_{2}(\exp )_{s}-N m F_{2}(\mathrm{th})_{s}\right]^{2} / M\right\}^{1 / 2}
\end{aligned}
$$

where $h m F 2(\exp )_{s}$ and $N m F 2(\exp )_{s}$ are the measured $h m F 2$ and $N m F 2 ; h m F 2(t h)_{s}$ and $N m F 2(t h)_{s}$ are the calculated (theoretical) $h m F 2$ and $N m F 2$ given by the IZMIRAN model, and $M$ is the number of measurements $(M=75$ for the time period considered).

Table 1 gives the calculated $\varepsilon_{1}$ and $\varepsilon_{2}$ for the 23-25 June period. We can see that the inclusion of $N_{2}(\mathrm{v}>0)$ in the calculations using model A improves the agreement between the calculated $N m F 2$ and the data. The rms error of $h m F 2$ is about the same whether $\mathrm{N}_{2}(\mathrm{v}>0)$ is included or not.

Figure 5 also shows results for model B (crosses) and model C (dotted lines), as described in Sect. 2. The differences in the rate of coefficients $K_{j}(j>0)$ between model A (solid line) and models $\mathrm{B}$ and $\mathrm{C}$ have little effect on the calculated electron density and temperature. The large difference between the rate coefficients for quenching of $\mathrm{O}^{+}\left({ }^{2} D\right)$ by atomic oxygen is mainly responsible for the offset between the solid lines and crosses, and the solid lines and dotted curves.

The two bottom rows of Table 1 give the rms errors of $N m F 2$ and $h m F 2$ using models $\mathrm{C}$ and $\mathrm{B}$. The rms error for $N m F 2$ is about the same for models $\mathrm{B}$ and $\mathrm{C}\left(K_{\mathrm{D}}=5 \times 10^{-12} \mathrm{~cm}^{3} \mathrm{~s}^{-1}\right)$ as for model $\mathrm{A}\left(K_{\mathrm{D}}\right.$ $\left.=10^{-10} \mathrm{~cm}^{3} \mathrm{~s}^{-1}\right)$. The rms error for $h m F 2$ is also nearly the same for the three models. Since our results are insensitive to the value of $K_{\mathrm{D}}$, they provide little evidence to support either value of $K_{\mathrm{D}}$.

\subsection{Vibrationally excited $\mathrm{NO}^{+}$ions}

The ion continuity equations for vibrationally unexcited and excited $\mathrm{NO}^{+}$ions are given by

$$
\begin{aligned}
\frac{\partial}{\partial t}\left[\mathrm{NO}^{+}(0)\right]= & q_{0}+\left(K_{4}+K_{6}\left[\mathrm{~N}_{2}\right]\right)\left[\mathrm{NO}^{+}(1)\right] \\
& -K_{1} N_{e}\left[\mathrm{NO}^{+}(0)\right] \\
\frac{\partial}{\partial t}\left[\mathrm{NO}^{+}(1)\right]= & q_{1}+\left(K_{5}+K_{7}\left[\mathrm{~N}_{2}\right]\right)\left[\mathrm{NO}^{+}(2)\right] \\
& -\left(K_{2} N_{e}+K_{4}+K_{6}\left[\mathrm{~N}_{2}\right]\right)\left[\mathrm{NO}^{+}(1)\right] \\
\frac{\partial}{\partial t}\left[\mathrm{NO}^{+}(2)\right]= & q_{2}-\left(K_{3} N_{e}+K_{5}+K_{7}\left[\mathrm{~N}_{2}\right]\right)\left[\mathrm{NO}^{+}(2)\right]
\end{aligned}
$$

Table 1. Modeled root mean square errors of $h m F 2$ and $N m F 2$

\begin{tabular}{lll}
\hline & $\varepsilon_{1}(\mathrm{~km})$ & $\varepsilon_{2}\left(10^{4} \mathrm{~cm}^{-3}\right)$ \\
\hline Model A with $\mathrm{N}_{2}(\mathrm{v})$ & 16.2 & 3.2 \\
Model A without $\mathrm{N}_{2}(\mathrm{v})$ & 16.2 & 4.2 \\
Model C with $\mathrm{N}_{2}(\mathrm{v})$ & 16.5 & 3.2 \\
Model B with $\mathrm{N}_{2}(\mathrm{v})$ & 17.3 & 3.3 \\
\hline
\end{tabular}


Table 2. Chemistry of unexcited $(\mathrm{v}=0)$ and vibrationally excited $(\mathrm{v}=1,2) \mathrm{NO}^{+}(\mathrm{v})$ ions

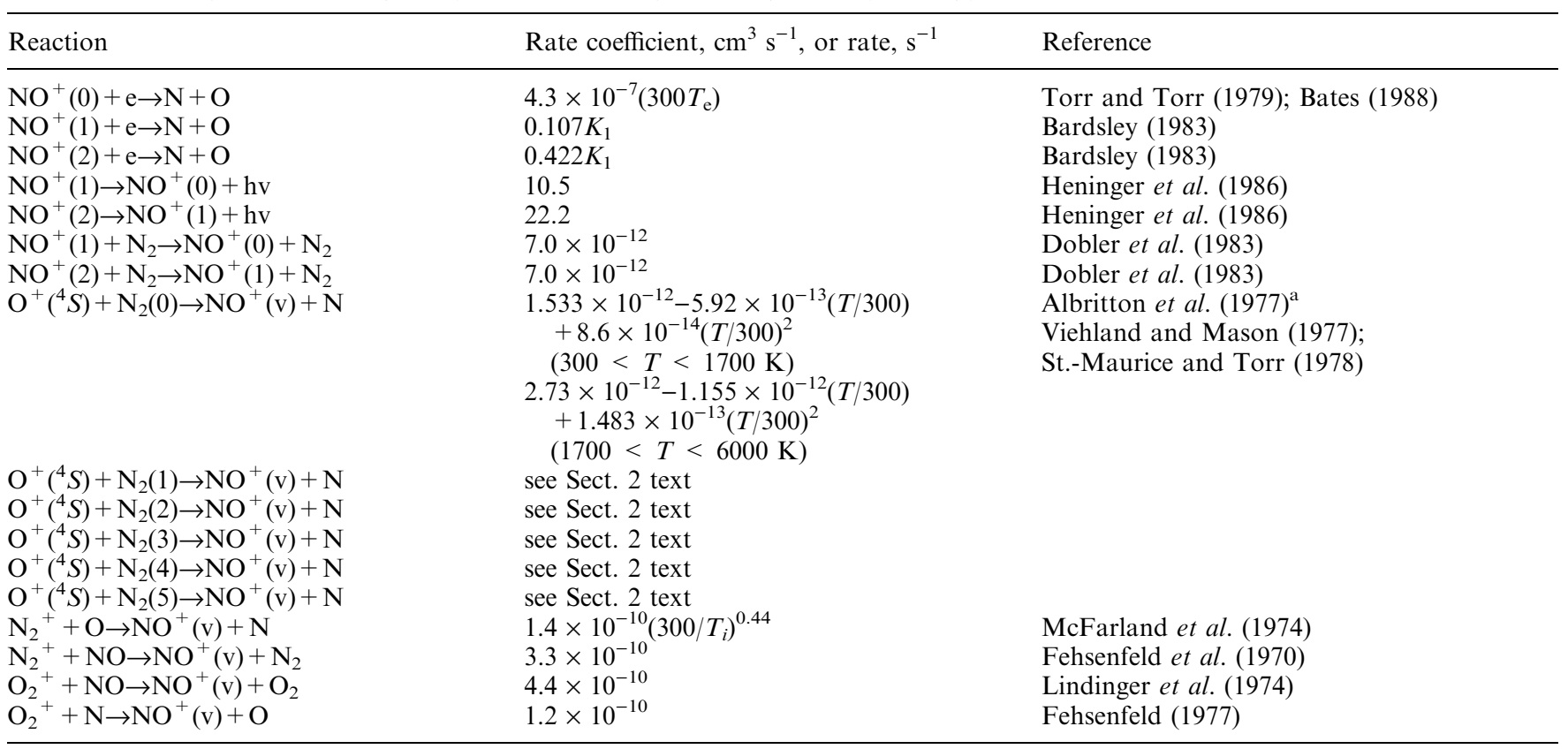

The effective temperature $T=\left(m_{i} T_{n}+m_{n} T_{i}\right) /\left(m_{i}+m_{\mathrm{n}}\right)+m_{i} m_{n} V_{d}^{2}\left[3 k\left(m_{i}+m_{n}\right)\right]^{-1}$, where $V_{d}$ is the plasma drift velocity relative to the neutrals

$$
\begin{aligned}
\frac{\partial}{\partial t}\left[\mathrm{NO}^{+}\right]= & q-\left(K_{1}\left[\mathrm{NO}^{+}(0)\right]\right. \\
& \left.+K_{2}\left[\mathrm{NO}^{+}(1)\right]+K_{3}\left[\mathrm{NO}^{+}(2)\right]\right) N_{e}
\end{aligned}
$$

where $\left[\mathrm{NO}^{+}\right]=\left[\mathrm{NO}^{+}(0)\right]+\left[\mathrm{NO}^{+}(1)\right]+\left[\mathrm{NO}^{+}(2)\right], t$ is the local time, $q_{v}$ are the total production rates of $\mathrm{NO}^{+}(\mathrm{v})$ ions by the chemical reactions 8-17 of Table 2 , $q=q_{0}+q_{1}+q_{2}$, and $K_{1}-K_{7}$ are the rate coefficients of the chemical reactions 1-7 displayed in Table 2.

If we take into account that in the ionosphere

$$
\left(K_{4}+K_{6}\left[\mathrm{~N}_{2}\right]\right) \gg K_{2} N_{e}, \quad\left(K_{5}+K_{7}\left[N_{2}\right]\right) \gg K_{3} N_{e},
$$

then for steady state conditions

$$
\begin{aligned}
& {\left[\mathrm{NO}^{+}(1)\right] /\left[\mathrm{NO}^{+}(0)\right]=X_{1}\left(q_{1}+q_{2}\right) q^{-1}} \\
& {\left[\mathrm{NO}^{+}(2)\right] /\left[\mathrm{NO}^{+}(0)\right]=X_{2} q_{2} q^{-1}}
\end{aligned}
$$

where $X_{1}=K_{1} N_{e} /\left(K_{4}+K_{6}\left[\mathrm{~N}_{2}\right]\right), X_{2}=K_{1} N_{e} /\left(K_{5}+K_{7}\right.$ $\left.\left[\mathrm{N}_{2}\right]\right)$.

As a result, $\left(\left[\mathrm{NO}^{+}(1)\right] /\left[\mathrm{NO}^{+}(0)\right]\right) \ll X_{1}$ and $\left(\left[\mathrm{NO}^{+}\right.\right.$ $\left.(2)] /\left[\mathrm{NO}^{+}(0)\right]\right) \ll X_{2}$.

According to our calculations, $X_{1}<6 \times 10^{-3}$ and $X_{2}<3 \times 10^{-3}$ for the magnetically quiet period on $23-$ 25 June 1986 . Therefore, vibrationally excited $\mathrm{NO}^{+}$ions form a very small percentage of the total $\mathrm{NO}^{+}$density. Since the rate coefficients $K_{2}$ and $K_{3}$ are smaller than $K_{1}$, the effect of $\mathrm{NO}^{+}(\mathrm{v}>0)$ ions on the recombination rate of electrons, and thus on the electron density, is negligible.

\subsection{Correction of incoherent scatter radar data using the IZMIRAN model}

Changes in ion composition and temperatures have similar effects on the shape of the ISR spectrum in the
F1 region. To deal with this ambiguity, an ion composition model is used in the reduction of the Millstone Hill ISR data. This has a gradual transition from $100 \%$ molecular ions $\mathrm{O}_{2}^{+}$and $\mathrm{NO}^{+}$(assumed mean molecular weight 31) below $120 \mathrm{~km}$ to $>99 \% \mathrm{O}^{+}$ ions above $230 \mathrm{~km}$, with $50 \%$ molecular ions at a transition altitude of $180 \mathrm{~km}$. At summer solar minimum, however, this transition altitude can lie well above $180 \mathrm{~km}$. For Millstone Hill at $250 \mathrm{~km}$ the latest version of the International Reference Ionosphere (IRI-95) (Bilitza, 1997) gives 47\% molecular ions at noon and $58 \%$ at midnight.

An error of such magnitude in the ion composition model used to reduce the ISR data may result in significant errors in the observed $T_{e}$ and $T_{i}$. Waldteufel (1971) published empirical expressions for multiplying factors to be applied to observed values of $T_{e}, T_{i}, T_{e} / T_{i}$, and $N_{e}$ derived from a spectrum processed with $p=\left[\mathrm{O}^{+}\right] / N_{e}=0$ to obtain values of these parameters when $p$ is modified.

We first used Millstone Hill ISR data processed with the standard ion composition model to derive initial altitude profiles of $T_{e}(1), T_{i}(1), N_{e}(1)$ and to obtain $h m F 2(1)$. These were then used in the IZMIRAN model to calculate the ion composition, and thus $p$ versus height. In these calculations the MSIS-86 model [O] was decreased by a factor 1.6 between 0500 LT and 0800 LT on 24 June at all altitudes. These values of $p$ were then used with the expressions of Waldteufel (1971) to derive corrected observed ISR profiles of $N_{e}(2), T_{e}(2)$, and $T_{i}(2)$, and to derive new values of $h m F 2(2)$. These corrected data are shown in Figs. 1-5, and the corrected $h m F 2$ values were used in the IZMIRAN model to calculate the modeled $N_{e}, h m F 2, T_{e}$, and $T_{i}$ also shown in Figs. 1-5. 

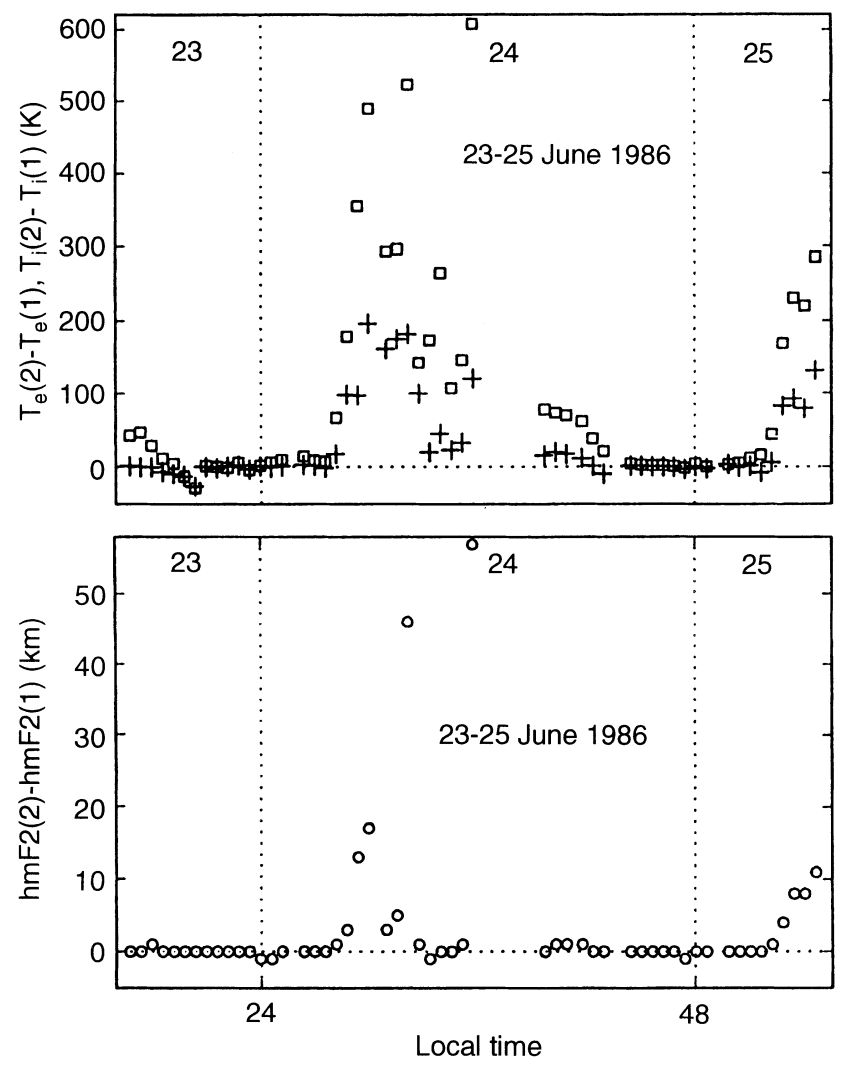

Fig. 6. The errors in observed $T_{e}$ (squares in the top panel) and $T_{i}$ (crosses in the top panel), and hmF2 (bottom panel) when the Millstone Hill standard ion composition model is used in reduction of the ISR data

Figure 6 shows the errors $T_{e}(2)-T_{e}(1)$ (squares in the top panel) and $T_{i}(2)-T_{i}(1)$ (crosses in the top panel) at the $F 2$ peak altitude, and the errors $h m F_{2}(2)-h m F_{2}(1)$ (bottom panel). There are some large differences in $T_{e}$ and $T_{i}$ as well as in $h m F 2$. Changes in $N m F 2$ are negligible as these profiles are calibrated with $f_{0} F 2$, so it is not possible for the peak value to change. Nevertheless, there are small changes in the $N_{e}$ profile shape leading to some changes in $h m F 2$. There are errors $h m F_{2}(2)-h m F_{2}(1)>10 \mathrm{~km}$ for measurements at 0527 , 0603,0814 , and $1150 \mathrm{LT}$ on 24 June, and at 0644 LT on 25 June. These are all times when large errors in $T_{e}$ and $T_{i}$ occurred. Large $h m F 2$ errors $(>10 \mathrm{~km})$ occur during periods when the value of $N m F 2$ is very close to the value of $N m F 1$. As a result, small changes in the $N_{e}$ profile shape due to use of the ISMIRAN model values of $p$ lead to either disappearance or appearance of a $\mathrm{G}$ condition.

A $\mathrm{G}$ condition as seen on an ionogram will exist if $f_{o F} 1>f_{o} F 2$, and this depends on the true concentration of $\mathrm{O}^{+}$relative to the molecular ions. However, for a $\mathrm{G}$ condition with $f_{O F} 1$ only slightly larger than $f_{O} F 2$, the ISR may or may not choose $h m F 1$ of $h m F 2$ as the peak with the larger electron density, depending on the ion composition model used in the data reduction process. Thus, the determination of a $\mathrm{G}$ condition from ISR data is sensitive both to the true $\mathrm{O}^{+}$relative concentration, and to the ion composition $(p)$ model assumed in the data reduction process.

\section{Conclusions}

We have presented a comparison between Millstone Hill incoherent scatter radar measurements of electron density and ion and electron temperature with results from the IZMIRAN model for the geomagnetically quiet period 23-25 June 1986. Anomalously low values of $h m F 2(<200 \mathrm{~km})$, seen as a $\mathrm{G}$ condition on ionograms, are a typical feature of the ionospheric $F$ region under these summer solar minimum conditions. We observed such low values of $h m F 2$ during the interval 0450-0850 LT on 24 June.

The IZMIRAN model was unable to reproduce the ionospheric $N_{e}$ profile at $0732 \mathrm{LT}$ when unadjusted MSIS-86 model densities were used, or when the MSIS$86 \mathrm{~N}_{2}$ and $\mathrm{O}_{2}$ densities were increased by a factor of 2 . In either case, the model gave a strong downward plasma drift which moved $\mathrm{O}^{+}$ions to lower altitudes where an increased recombination rate reduced the electron density and created an $F$ region peak (an $F 1$ peak) due to $\mathrm{O}^{+}$ ions and $\mathrm{NO}^{+}$and $\mathrm{O}_{2}^{+}$ions below $200 \mathrm{~km}$. However, a large disagreement between observed and modeled $N_{e}$ was found in the topside, which was nearly a factor of 6 in the altitude range $400-500 \mathrm{~km}$. However, the IZMIRAN model was able to reproduce the measurements at 0732 LT when the MSIS-86 atomic oxygen density was decreased by a factor of 1.6. With this adjustment, the model gave an upward plasma drift, topside $N_{e}$ in reasonable agreement with the data, an $F 2$ peak composed of $\mathrm{O}^{+}$ions, and an $F 1$ peak below $200 \mathrm{~km}$ composed of $\mathrm{O}^{+}, \mathrm{NO}^{+}$, and $\mathrm{O}_{2}{ }^{+}$ions with a peak electron density $\mathrm{NmF1}>\mathrm{NmF2}$. This result indicates that MSIS86 model may need improvement during geomagnetically quiet periods in summer at solar minimum.

We find that inclusion of $\mathrm{N}_{2}(\mathrm{v})$ in the model results in reductions in $N m F 2$ of typically $5-10 \%$, but as large as $15 \%$, improving the agreement with the data. Thus, the effects of $\mathrm{N}_{2}(\mathrm{v})$ have been found here to be a little more important during 23-25 June 1986 than they were during the geomagnetically quiet day 18 September 1984 (Richards et al., 1989), also at solar minimum. Our results have been shown to be insensitive to the choice of the rate coefficient for quenching of $\mathrm{O}^{+}\left({ }^{2} D\right)$ by atomic oxygen. It was found that vibrationally excited $\mathrm{NO}^{+}$ ions form a very small percentage of the total $\mathrm{NO}^{+}$ density, and the effect of $\mathrm{NO}^{+}(\mathrm{v}>0)$ ions on the electron density is negligible.

Millstone Hill measurements of $N_{e}, T_{e}$, and $T_{i}$ were corrected using values of the ratio $\left[\mathrm{O}^{+}\right] / N_{e}$ given by the IZMIRAN model. Large errors were found at times $T_{e}, T_{i}$, and $h m F 2$ data derived using the standard Millstone Hill ion composition model, due to the large percentage of molecular ions found above $180 \mathrm{~km}$. Determination of a $G$ condition from ISR data is sensitive both to the true $\mathrm{O}^{+}$relative concentration, and to the ion composition model assumed in the data reduction process.

Acknowledgements. A. V. Pavlov was supported by grant 96-0564031 from the Russian Foundation of Fundamental Research. Millstone Hill radar data were analyzed using the support of the 
U S. National Science Foundation cooperative agreement ATM94-08609 to the Massachusetts Institute of Technology.

Topical Editor D. Alcaydé thanks J. Titheridge and L. Zhu for their help in evaluating this paper.

\section{References}

Abdou, W. A., D. G. Torr, P. G. Richards, M. R. Torr, and E. L. Breig, Results of a comprehensive study of the photochemistry of $\mathrm{N}_{2}{ }^{+}$in the ionosphere, J. Geophys. Res., 89, 9069-9079, 1984.

Albritton, D. L., I. Dotan, W. Lindinger, M. McFarland, J. Tellinghuisen, and F. C. Fehsenfeld, Effects of ion speed distributions in flow-drift tube studies on ion-neutral reactions, J. Chem. Phys., 66, 410-421, 1977.

Banks, P. M., R. W. Schunk, and W. J. Raitt, $\mathrm{NO}^{+}$and $\mathrm{O}^{+}$in the high latitude $F$ - region, Geophys. Res. Lett. 1, 239-242, 1974.

Bardsley, J. N., Dissociative recombination of electrons with $\mathrm{NO}^{+}$ ions, Planet. Space Sci., 31, 667-670, 1983.

Bates, D. R., Recombination in the normal $E$ and $F$ layers of the ionosphere, Planet. Space Sci., 36, 55-63, 1988.

Bilitza, D., Progress report on IRI status, Adv. Space Res., 10(11), 3-5, 1990

Bilitza, D., International reference ionosphere - status 1995/96, Adv. Space Res., 20 (9), 1751-1754, 1997.

Buonsanto, M. J., Observed and calculated $F 2$ peak heights and derived meridional winds at mid-latitudes over a full solar cycle, J. Atmos. Terr. Phys., 52, 223-240, 1990.

Dobler, W., W. Federer, F. Howorka, W. Lindinger, M. DurupFerguson, and E. Ferguson, Vibrational relaxation of $\mathrm{NO}^{+}(\mathrm{v})$ ions in neutral collisions, J. Chem. Phys., 79, 1543-1544, 1983.

Fehsenfeld, F. C., The reaction of $\mathrm{O}_{2}^{+}$with atomic nitrogen and $\mathrm{NO}^{+} \cdot \mathrm{H}_{2} \mathrm{O}$ and $\mathrm{NO}_{2}^{+}$with atomic oxygen, Planet. Space Sci. 25, 195-196, 1977 .

Fehsenfeld, F. C., D. B. Dunkin, and E. E. Ferguson, Rate constants for the reaction of $\mathrm{CO}_{2}{ }^{+}$with $\mathrm{O}, \mathrm{O}_{2}$, and $\mathrm{NO} ; \mathrm{N}_{2}^{+}$with $\mathrm{O}$ and $\mathrm{NO}$; and $\mathrm{O}_{2}^{+}$with $\mathrm{NO}$, Planet. Space Sci., 18, 1267-1269, 1970.

Ferguson, E. E., Comment on "The effect of thermospheric chemistry of a resonant charge-exchange reaction involving vibrationally excited $\mathrm{N}_{2}^{+}$ions with atomic oxygen" by W. A. Abdou et al., J. Geophys. Res., 89, 399-400, 1984.

Ferguson, E. E., N. G. Adams, D. Smith, and E. Alge, Rate coefficients at $300 \mathrm{~K}$ for the vibrational energy transfer reactions from $\mathrm{N}_{2}(\mathrm{v}=1)$ to $\mathrm{O}_{2}^{+}(\mathrm{v}=0)$ and $\mathrm{NO}^{+}(\mathrm{v}=0)$, J. Chem. Phys., 80, 6095-6098, 1984

Fox, J. L., The vibrational distribution of $\mathrm{O}_{2}^{+}$in the dayside ionosphere, Planet. Space. Sci., 34, 1241-1252, 1986.

Fox, J. L. and A. Dalgarno, The vibrational distribution on $\mathrm{N}_{2}^{+}$in the terrestrial ionosphere, J. Geophys. Res., 90, 7557-7567, 1985

Fukao, S., W. L. Oliver, Y. Onishi, T. Takami, T. Sato, T. Tsuda, M. Yamamoto, and S. Kato, $F$-region seasonal behavior as measured by the MU radar, J. Atmos. Terr. Phys., 53, 599-618, 1991

Hagan, M. E., Quiet time upper thermospheric winds over Millstone Hill between 1984 and 1990, J. Geophys. Res., 98, 3731-3739, 1993

Häggström, I., and P. N. Collis, Ion composition changes during $F$ region density depletions in the presence of electric fields at auroral latitudes, J. Atmos. Terr. Phys., 52, 519-529, 1990.

Hedin, A. E., MSIS-86 thermospheric model, J. Geophys. Res., 92, 4649-4662, 1987.

Heninger, M., S. Fenistein, M. Durup-Ferguson, E. E. Ferguson, X. R. Mun, and G. Manlaire, Radiative lifetime for $\mathrm{V}=1$ and $\mathrm{V}=2$ ground state $\mathrm{NO}^{+}$ions, Chem. Phys. Lett., 131, 439-443, 1986

Krinberg, I. A. and A. V. Taschilin, Ionosphere and plasmasphere, Nauka, Moscow, 1984 (in Russian).
Lindinger, W., F. C. Fehsenfeld, A. L. Schmeltekopf, and E. E. Ferguson, Temperature dependence of some ionospheric ionneutral reactions from $300 \mathrm{~K}-900 \mathrm{~K}$, J. Geophys. Res., 79, 47534756, 1974.

McFarland, M., D. L. Albritton, F. C. Fehsenfeld, E. E. Ferguson, and A. L. Schmeltekopf, Energy dependence and branching ratio of the $\mathrm{N}_{2}^{+}+\mathrm{O}$ reaction, J. Geophys. Res., 79, 2925-2926, 1974

Oliver, W. L., Neutral and ion composition changes in the $F$ region over Millstone Hill during the equinox transition study, $J$. Geophys. Res., 95, 4129-4134, 1990.

Oppenheimer, M., E. R. Constantinides, K. Kirby-Docken, G. A. Victor, A. Dalgarno, and J. H. Hoffman, Ion photochemistry of the thermosphere from Atmosphere Explorer C measurements, J. Geophys. Res., 82, 5485-5492, 1977.

Pavlov, A. V., Possible accuracy of theoretical forecasts of the major ionospheric parameters, in Forecast of disturbances in the ionosphere and magnetosphere and solar activity (in Russian), Ed R. A. Zevakina and V. N. Obridko, pp 177-192, Nauka, Moscow, 1987.

Pavlov, A.V., The role of vibrationally excited nitrogen in the ionosphere, Pure Appl. Geophys., 127, 529-544, 1988.

Pavlov, A.V., The role of vibrationally excited nitrogen in the formation of the mid-latitude negative ionospheric storms, Ann. Geophysicae, 12, 554-564, 1994.

Pavlov, A. V., Mechanisms of the electron density depletion in the SAR arc region, Ann. Geophysicae, 14, 211-221, 1996.

Pavlov, A. V., Subauroral red arcs as a conjugate phenomenon: comparison of OV1-10 satellite data with numerical calculations, Ann. Geophysicae, 15, 984-998, 1997.

Pavlov, A. V., and M. J. Buonsanto, Comparison of model electron densities and temperatures with Millstone Hill observations during undisturbed periods and the geomagnetic storms of March 16-23 and April 6-12, 1990, Ann. Geophysicae, 15, 327344, 1997.

Pavlov, A. V. and A. A. Namgaladze, Vibrationally excited molecular nitrogen in the upper atmosphere, a review, $G e$ omagn. Aeron., 28, 705-721, 1988 (in Russian).

Richards, P.G., An improved algorithm for determining neutral winds from the height of the $F 2$ peak electron density, $J$. Geophys. Res., 96, 17839-17846, 1991.

Richards, P. G., D. G. Torr, M. J. Buonsanto, and K. L. Miller, The behavior of the electron density and temperature at Millstone Hill during the equinox transition study September 1984, $J$. Geophys. Res., 94, 16969-16975, 1989.

Richards, P. G., J. A. Fennelly, and D. G. Torr, EUVAC: a solar EUV flux model for aeronomic calculations, J Geophys. Res., 99, 8981-8992, 1994a.

Richards, P. G., D. G. Torr, B. W. Reinisch, R. R. Gamache, and P. G. Wilkinson, $F 2$ peak electron density at Millstone Hill and Hobart: comparison of theory and measurements at solar maximum, J. Geophys. Res., 99, 15005-15016, 1994b.

Schmeltekopf, A. L., E. E. Ferguson, and F. C. Fehsenfeld, Afterglow studies of the reactions $\mathrm{He}^{+}, \mathrm{He}\left(2^{3} S\right)$, and $\mathrm{O}^{+}$ with vibrationally excited $\mathrm{N}_{2}, J$. Chem. Phys., 48, 2966-2973, 1968.

Schunk, R. W., W. J. Raitt, and P. M. Banks, Effects of electric fields on the daytime high-latitude $E$ and $F$ regions, $J$. Geophys. Res., 80, 3121-3130, 1975.

St.-Maurice, J.-P. and D. G. Torr, Nonthermal rate coefficients in the ionosphere: The reactions of $\mathrm{O}^{+}$with $\mathrm{N}_{2}, \mathrm{O}_{2}$ and $\mathrm{NO}, J$. Geophys. Res., 83, 969-977, 1978.

Torr, M. R., and D. G. Torr, Recombination of $\mathrm{NO}^{+}$in the midlatitude trough and the polar ionization hole, J. Geophys. Res., 84, 4316-4320, 1979

Torr, M. R. and D. G. Torr, The role of metastable species in the thermosphere, Rev. Geophys. Space Phys., 20, 91-144, 1982.

Torr, M. R., D. G. Torr, P. G. Richards, and S. P. Yung, Mid- and low-latitude model of thermospheric emissions. $1, \mathrm{O}^{+}\left({ }^{2} P\right)$ 
$7320 \AA$, and $\mathrm{N}_{2}(2 P) 3371 \AA ̊$, J. Geophys. Res., 95, 21147-21168, 1990.

Van Zandt, T. E., and T. F. O' Malley, Rate coefficient for the reaction of $\mathrm{O}^{+}$with vibrationally excited $\mathrm{N}_{2}$, J. Geophys. Res., 78, 6818-6820, 1973.

Viehland, L. A. and E. A. Mason, Statistical-mechanical theory of gaseous ion-molecule reactions in an electrostatic field, J. Chem. Phys., 66, 422-434, 1977.

Waldteufel, P., Combined incoherent-scatter $F 1$-region observations, J. Geophys. Res., 76, 6995-6999, 1971.
Yonezawa, T., A consideration of the effective recombination coefficient in the E-region of the ionosphere, J. Atmos. Terr. Phys., 30, 473-478, 1968.

Zipf, E. C., A laboratory study on the dissociative recombination of vibrationally excited $\mathrm{O}_{2}^{+}$ions, J. Geophys. Res., 85, 42324236, 1980.

Zipf, E. C., The excitation of the $\mathrm{O}\left({ }^{1} S\right)$ state by the dissociative recombination of $\mathrm{O}_{2}^{+}$ions: electron temperature dependence, Planet. Space Sci., 36, 621-628, 1988. 